\title{
Reflexiones desde la universidad sobre educación en derechos humanos y para la paz
}

\author{
Reflections from the university on an education in human rights and \\ intended for peace
}

Reflexões desde a universidade sobre a educação em direitos humanos e para a paz

\author{
Celina Trimiño Velásquez ${ }^{1}$ \\ Luisa Amézquita Aguirre ${ }^{2}$ \\ Universidad Pedagógica y Tecnológica de Colombia, Colombia
}

Recepción: 19/11/2017

Evaluación: 16/06/2018

Aceptación: 29/06/2018

Artículo de Revisión

DOI: $10.19053 / 01227238.8564$

\section{RESUMEN}

A la universidad le compete el reto y la responsabilidad de contribuir en la formación en derechos humanos, así como suscitar espacios de reflexión en torno a la paz como aporte transcendental para la sociedad colombiana. Así, el objetivo es analizar la relevancia de educar en derechos humanos y para la paz, las características de los conflictos y el papel de la universidad en estas materias y sus propuestas. El artículo se enmarca en los estudios críticos de las temáticas que son necesarias para aproximarse - en un escenario de posacuerdos en Colombia- a los procesos de cimentación de la paz. El método se centró en una amplia revisión bibliográfica y la estrategia metodológica se enfocó en el análisis de los temas desarrollados, facilitando el diálogo interdisciplinario entre las teorías, ideas o planteamientos sobre conflictos, derechos humanos y paz. En este contexto, se sitúan las pedagogías alternativas que fortalecen la visión de los derechos humanos, articulados en una educación para la paz desde la interculturalidad. Se puede colegir que, si bien la universidad avanza en la elaboración y puesta en marcha de nuevas propuestas, es imprescindible continuar en la consolidación de una cul-

1 Doctora en Derechos Fundamentales de la Universidad Carlos in de Madrid-España. Profesora de la Universidad Pedagógica y Tecnológica de Colombia. Grupo de Investigación Feminismos, Géneros y Derechos Humanos (GIEPEG). Correo electrónico: celinatrimino@gmail.com; celinatrimino@uptc.edu.co

2 Doctora en Ciencias de la Educación, especialidad en Pedagogía Escolar de la Università Pontificia Salesiana di Roma, Italia. Profesora de la Universidad Pedagógica y Tecnológica de Colombia. Grupo de Investigación Feminismos, Géneros y Derechos Humanos (GIEPEG).Correo electrónico: luisa.amezquita@uptc.edu.co; luisauptc@hotmail.com 
tura de paz, lo que conlleva a la formación de ciudadanas y ciudadanos que puedan potenciar sus capacidades humanas en la construcción de la paz en un país que ha vivido inmerso en un largo conflicto armado.

Palabras clave: Revista Historia de la Educación Latinoamericana; universidad colombiana; educación; derechos humanos; conflictos y paz.

\section{ABSTRACT}

The university has the challenge and the responsibility to train in human rights, as well as to promote spaces for reflection on peace as a transcendental contribution to the Colombian society. In this way, the aim of this work is to analyze the relevance of educating in both human rights for peace, and to study the characteristics of conflicts and the role of the university and its proposals in these scenarios.

This article is part of the critical studies of the topics that are necessary to approach the processes of peace foundations in a post-agreement scenario in Colombia. The method consisted in an extensive literature review and the methodological strategy focused on the analysis of the developed topics, thus facilitating the interdisciplinary dialogue between theories, ideas or approaches on conflicts, human rights, and peace.

In this context, we find alternative pedagogies that strengthen the vision of human rights, articulated in an education for peace from interculturality. It can be inferred that, although the university advances in the preparation and implementation of new proposals, it is essential to continue the process of consolidating a culture of peace, which leads to the formation of citizens who can enhance their human capabilities in the construction of peace in a country that has lived immersed in a long armed conflict.

Keywords: Journal History of Latin American Education; Colombian university; education; human rights; conflicts and peace.

\section{RESUMO}

À universidade compete o desafio e a responsabilidade de contribuir na formação em direitos humanos, assim como suscitar espaços de reflexão em torno da paz como contribuição transcendental para a sociedade colombiana. Assim, o objetivo é analisar a relevância de educar em direitos humanos para a paz, as características dos conflitos e o papel da universidade nestas matérias e suas propostas. $\mathrm{O}$ artigo faz parte dos estudos críticos das temáticas que são necessárias para aproximar-se-em um cenário de pósacordos na Colômbia - dos processos de consolidação da paz. O método se centrou em uma ampla revisão bibliográfica e a estratégia metodológica focou na análise dos temas desenvolvidos, facilitando o diálogo interdisciplinar entre as teorias, ideias ou abordagens sobre conflitos, direitos humanos e paz. Neste contexto, se situam as pedagogias alternativas que fortalecem a visão dos direitos humanos, articulados em uma educação para a paz desde a Interculturalidade. Pode-se concluir que, embora a universidade avance na elaboração e coloque em marcha novas propostas, é imprescindível continuar a consolidação de uma cultura de paz, o que implica a formação de cidadãs e cidadãos que possam potencializar suas capacidades humanas na construção da paz em um país que viveu imerso em um longo conflito armado.

Palavras-chave: Revista História da Educação Latino-americana; universidade colombiana; educação; direitos humanos; conflitos e paz. 


\section{INTRODUCCIÓN}

En un escenario de posacuerdos, para aproximarse a la construcción de la paz en Colombia es necesario el análisis de los conflictos, los derechos humanos y la paz desde una visión crítica e intercultural. Aunque el sistema educativo tiene el compromiso de incorporar estas temáticas en todos sus espacios académicos, es claro que no solo a la educación formal le corresponde esta gran responsabilidad o que esta sea suficiente para transformar las realidades. También es cardinal la educación no formal e informal, lo que se concreta a través de otros medios. Asimismo, el sector privado no puede eludir su responsabilidad social, pero no contemplada desde lo caritativo o tan siquiera lo filantrópico, sino en cumplimiento de sus obligaciones como parte integrante de una sociedad que debe priorizar el bien común.

Visto lo anterior, la intervención del Estado colombiano y de los poderes públicos es decisiva para orientar y garantizar lo necesario para concretar los cambios que permitan a las sociedades resolver de manera conjunta sus dificultades, formar ciudadanas/os con un carácter deliberativo y crear las condiciones para potenciar las capacidades de los seres humanos, en el entendido de que la consecución de la paz es una tarea colectiva, reto que se constituye en trascendental si en realidad se quiere privilegiar la vida y el bienestar general por encima de los conflictos armados, que benefician o interesan a algunas personas o grupos. En este marco, se considera que a la universidad le compete un papel crucial tanto dentro de las instituciones en la formación integral del estudiantado, como de cara a la sociedad a través de sus estudios, investigaciones, publicaciones y actividades, con el fin de poder participar con buenos razonamientos y de manera activa en la construcción de la paz. Para acercarse a la comprensión de algunas de las problemáticas que atraviesan a Colombia, el método se enfocó en la búsqueda de las fuentes de carácter nacional e internacional, se realizó un examen bibliográfico encauzado a explorar la información de diferentes autoras/es sobre las temáticas revisadas. La estrategia metodológica se centró en la interpretación de textos, anteponiendo el diálogo interdisciplinario entre las teorías y planteamientos sobre conflictos, derechos humanos y paz, con el propósito de mostrar su interrelación, la relevancia de su estudio y la importancia de la universidad en el transcurso de su educación, tomando como referencia las reflexiones realizadas desde la Universidad Pedagógica y Tecnológica de Colombia.

Los aportes de la universidad pretenden ser una contribución que conlleva ir de la mano de las comunidades urbanas y rurales para transitar los derroteros que permitan avanzar en el proceso de construcción de paz. Lo anterior podrá hacerse realidad con el apoyo de las pedagogías alternativas que faciliten a la educación universitaria cumplir con su función de educar personas empoderadas y con argumentos para que, en conjunción con las experiencias de la población, participen de manera activa en la consecución de una vida mejor. 


\section{La relevancia de educar en derechos humanos y para la paz}

Este punto cobra protagonismo si se considera la necesidad de hacer evidente el compromiso individual y colectivo de los actos de cada quien. Las personas, como agentes morales, tienen la capacidad de formarse en el reconocimiento de las otras/os y el respeto a la diferencia de los seres humanos. Al respecto, Martha Nussbaum denota que “(...) los seres humanos se comportan mal cuando no se sienten personalmente responsables de sus actos. El individuo se conduce mucho peor bajo la máscara del anonimato, como parte de una masa sin rostro, que cuando se siente observado y responsabilizado como tal"3. Así pues, el sistema educativo junto con la sociedad, la familia, el Estado y otras instituciones, participan de manera decisoria en este proceso de formación en derechos humanos y para la paz, aún más en contextos de posacuerdos ${ }^{4}$. Los hechos históricos demuestran que es esencial insistir en el reconocimiento recíproco de la humanidad de todos los seres humanos para que no proliferen teorías, doctrinas, ideologías o planteamientos que discriminen o excluyan al otro o a la otra por cualquier razón, que con frecuencia escuda el odio a lo diferente, propiciando su exterminio, aniquilación o genocidio; por tanto, en todos los tiempos es imprescindible acentuar, en la teoría y en la práctica, que es un deber moral aprender a respetar a las demás personas y expresarlo en todos los casos ${ }^{5}$. En esta perspectiva, Judith Butler razona sobre las guerras y los procedimientos para llevarlas a cabo. La autora hace reflexionar acerca de los acontecimientos que estas suscitan y las noticias que se generan al respecto, de igual forma se detiene en la comprensión de los marcos de guerra y plantea que cuando hay intervención militar en los diferentes países o en los conflictos armados, se debe luchar conjuntamente para "superar - en nombre de un mundo interdependiente y dentro de los términos de una forma más radical de igualitarismo - la desigualdad radical que caracteriza la diferencia entre las vidas por las que se puede llevar duelo y las que no lo merecen" ${ }^{\prime \prime}$, aludiendo tanto a las fuerzas militares como a la población civil, que es valorada según el país, grupo o clase social a la que pertenezcan; así, hay una población que es protegida y otra no.

A lo anterior es oportuno añadir que, como afirma Jen Burnley, "el conflicto es un modo de comunicación y una parte inevitable de nuestras vidas (...) la educación sobre el conflicto constituye una parte esencial de la educación de la paz y debe ser materia de interés para todos los educadores, tanto en la esfera de la educación formal como en la informal" ${ }^{7}$. De ahí que, en este ámbito, la universidad debe implicarse en el debate académico con el fin de dilucidar las caracte-

3 Martha C. Nussbaum, Sin fines de lucro. Por qué la democracia necesita de las humanidades (Madrid: Katz Editores, 2010 ), 72.

4 Cfr. Elisabeth Porter, Construir la paz. La experiencia y el papel de las mujeres en perspectiva internacional (Barcelona: Institut Català Internacional per la Pau (ICIP), Edicions Bellaterra, S. L., 2012), 62.

5 Temática tratada en profundidad por Martha C. Nussbaum, op. cit., 72.

6 Judith Butler, Violencia de Estado, guerra, resistencia. Por una nueva política de izquierda (entrevista de Daniel Gamper Sachse) (España: Centro de Cultura Contemporánea de Barcelona, 2011), 10, 13, 14, 20, 22, 29.

7 Jen Burnley, "Conflicto", en Educación para la paz. Cuestiones, principios y práctica en el aula. Comp. por David Hicks (Madrid: Ministerio de Educación y Cultura / Morata, 1999), 73- 92, 73. 
rísticas de los distintos conflictos que subyacen en todas las sociedades. Este es un camino para puntualizar el compromiso de la academia en la formación de ciudadanos/as que comprendan sus conflictos, los compartan y participen desde sus comunidades en su discernimiento, haciendo de la democracia participativa algo que se acerque a la realidad. Al respecto, Johan Galtung anota que "una forma simple de construir una cultura de paz sería construir conocimientos y destrezas prácticas sobre conflicto desde las guarderías hasta los doctorados"8; en este contexto, corresponde a todos los niveles de educación comprometerse en el estudio de dichas problemáticas.

En este marco, las políticas públicas son decisivas para orientar la discusión y propiciar las condiciones con el fin de que se concreten los planteamientos sobre los derechos humanos y la construcción de paz. André-Noël Roth recuerda que "la cuestión de los derechos humanos empezó a ser un componente institucional de la política colombiana, de forma explícita, a partir de 1987, bajo la presidencia de (...) Virgilio Barco, con la creación de la Consejería Presidencial para los Derechos Humanos" ${ }^{\prime \prime}$. Es así que Colombia, como Estado Social de Derecho, consagra en la Constitución Política de 1991 los principios para cimentar lo relativo a los derechos humanos y el derecho a la paz. El Estado a través de las políticas públicas orientadas a la educación en derechos humanos y para la paz, facilita la comprensión del significado de los diálogos, de los acuerdos de paz y de las rutas en los posacuerdos. Asimismo, permite resaltar la centralidad de los derechos de las víctimas y su papel en los procesos de paz sin soslayar la participación de la sociedad en esta construcción. Por demás, "será, pues, clave la educación formal e informal, serán esenciales las decisiones tomadas a lo largo de la vida, pero también la creación de instituciones y organizaciones que refuercen el reconocimiento de los sin poder"10.

De acuerdo con lo anterior, lo establecido en la Carta Constitucional de Colombia adquiere relevancia en la propuesta de la Política Integral de Derechos Humanos 2014-2034, que está conformada por cinco ejes, dentro de los cuales se puede mencionar el concerniente a "Ciudadanía, Cultura y Educación en Derechos Humanos y Paz", con sus cuatro componentes estratégicos: -Derechos Civiles y Políticos; -Derechos Económicos, Sociales, Culturales y Ambientales (DESCA); -Agenda de Transición y construcción de Paz; y -Aplicación de derechos transversales de grupos y sectores discriminados ${ }^{11}$. Como se evidencia, esta política recoge una gran parte de los derechos humanos conquistados por las luchas de los movimientos sociales, incorporando demandas de poblaciones históricamente excluidas. Lo expresado se traduce en los denominados enfoques dife-

8 Johan Galtung, Tras la violencia, 3R: reconstrucción, reconciliación, resolución. Afrontando los efectos visibles e invisibles de la guerra y la violencia (Bilbao: Bakeaz, Gernika Gogoratuz, 1998), 74.

9 André-Noël Roth D., Discurso sin compromiso. La política pública de derechos humanos en Colombia. Antecedentes históricos de los derechos humanos. Qué es una política pública. Actitud del Estado colombiano (Bogotá: Ediciones Aurora, 2006), 103.

10 Adela Cortina, Aporofobia, el rechazo al pobre. Un desafío para la democracia (España: Paidós, 2017), 81.

11 Cfr. Programa de las Naciones Unidas para el Desarrollo. PNud. De la violencia a la Sociedad de los Derechos: Propuesta de Politica Integral de Derechos Humanos 2014-2034, coord. ed. Îtalo Andrés Velásquez y Carlos Alberto Rivera (Bogotá: Proceso Tripartito de Construcción Participativa de la Política Pública de DDHн y DiH, PNUd, 2013), 27, 37, 76, 77, 99. 
renciales y su relación con las intersecciones tales como género, raza/etnicidad, clase social, orientación sexual, discapacidad y edad, es decir, en el respeto a la diferencia, la eliminación de las discriminaciones y el fortalecimiento de los derechos humanos. Toda vez que "la capacidad de producción social, cultural y política de la escuela y de los procesos adelantados por organizaciones sociales en la construcción de la memoria, significan y demandan producciones de prácticas emancipadoras en torno a la paz y a los derechos humanos"12, el sistema educativo se erige como un elemento clave para reforzar la reflexión, formación, puesta en marcha y acompañamiento de estos temas. El contenido del decálogo propuesto por Susana Sacavino ${ }^{13}$ sirve como guía para motivar, proyectar y ejecutar acciones en el sistema educativo, relacionadas con la educación en derechos humanos y para la paz.

\section{Pensar sobre conflictos, derechos humanos y paz}

Para consolidar la relevancia de formar en derechos humanos y para la paz, es necesario acercarse a sus concepciones; Xesús Jares considera que

(...) la educación para los derechos humanos como un proceso educativo continuo y permanente, asentado en el concepto amplio y procesual de derechos humanos como tal ligada al desarrollo, la paz y la democracia-, y en la perspectiva positiva del conflicto, que pretende desarrollar la noción de una cultura de derechos que tiene como finalidad la defensa de la dignidad humana, de la libertad, de la igualdad, de la solidaridad, de la justicia, de la democracia y de la paz. Como componente de la educación para la paz, la educación para los derechos humanos es una forma particular de educación en valores ${ }^{14}$.

Por lo tanto, es imprescindible abordar el estudio de los postulados básicos en la materia que permitan consolidar un cuerpo teórico de análisis como sustento de los planteamientos aquí esbozados. Antes de adentrarse en las concepciones de los derechos humanos y la paz, es oportuno detenerse a pensar en la idea de conflicto, toda vez que los conflictos hacen parte de la convivencia humana y por tanto las personas están en capacidad de plantear la resolución de estos por vías no violentas, como lo señala Estanislao Zuleta.

Si alguien me objetara que el reconocimiento previo de los conflictos y las diferencias, de su inevitabilidad y su conveniencia, arriesgaría paralizar en nosotros la decisión y el entusiasmo en la lucha por una sociedad más justa, organizada y racional, yo le replicaría que para mí una sociedad mejor es una sociedad capaz de tener mejores conflictos. De reconocerlos y de contenerlos. De vivir no a pesar de ellos,

\footnotetext{
12 Piedad Ortega Valencia, "Las urgencias de una cátedra de la paz en la escuela: Rutas de formación", Fecode, Revista Educación y Cultura, n. ${ }^{\circ} 109$ (2015): 13.

13 Cfr. Susana Sacavino, "Educación para la paz y la No Violencia en la formación de docentes", La Tarea, n. ${ }^{\circ} 20$, (2009): 12-18.

14 Xesús R. Jares, Educación y Derechos Humanos. Estrategias didácticas y organizativas (Madrid: Editorial Popular, 1999$), 81$.
} 
sino productiva e inteligentemente en ellos. Que sólo un pueblo escéptico sobre la fiesta de la guerra, maduro para el conflicto, es un pueblo maduro para la paz ${ }^{15}$.

Lo expuesto puede complementarse con algunas de las características de los conflictos, compendiadas por Xesús Jares, quien también piensa que el conflicto es un fenómeno multidimensional que tiene una explicación en perspectiva multidisciplinaria, destacando que el ser humano es educable, es decir, se puede educar ${ }^{16}$; por lo demás, sin olvidar que la concepción de conflictos es amplia pues no se refiere únicamente a los conflictos armados, tanto es que "Colombia tiene una larga tradición de conflictos sociales, económicos y políticos que en múltiples ocasiones han derivado en fuertes conflictos armados"17, como el que este país ha estado viviendo por más de sesenta años ${ }^{18}$. Después del proceso iniciado en el $2012^{19}$ y que se ha llevado a cabo por más de cuatro años en Colombia, se firma el Acuerdo final para la terminación del conflicto y la construcción de una paz estable y duradera en noviembre de $2016^{20}$, que busca la solución al conflicto armado, las acciones de diálogo político no pueden dejar de lado la preparación de la sociedad para la construcción de una paz duradera que se cimente y se mantenga más allá del posacuerdo, pues como lo argumenta Kristian Herbolzheimer, "así como el estallido de violencia no se puede entender sin analizar las causas subyacentes, la paz también necesita un largo proceso de incubación para hacerse palpable" ${ }^{\prime 21}$, desde luego es imprescindible fortalecer el estudio de la paz.

En conexión con los conflictos y la paz, Paulo Freire expresaba claramente que "la lucha por la paz, que no significa la lucha por la abolición ni siquiera por la negación de los conflictos, sino por la confrontación justa, crítica de los mismos y la búsqueda de soluciones correctas para ellos, es una exigencia imperiosa de nuestra época"22, y aunque este escrito data de 1997, puede afirmarse que los planteamientos de este autor mantienen su vigencia. Esto lleva a examinar los derechos humanos engarzados con la paz, toda vez que, como lo argumenta Xesús Jares, “(...) la teoría de la paz es la teoría de los derechos humanos (...).

15 Estanislao Zuleta, Sobre la guerra (Cali: Universidad del Valle) http://catedraestanislao.univalle.edu.co/ (22 de nov. de 2015).

16 Cfr. Xesús R. Jares, Educación para la paz. Su teoría y su práctica (Madrid: Editorial Popular, 1991), 110-111.

17 Carlos Salgado Araméndez, "Proyecto planeta paz. Estrategia social de construcción de paz", en La vía ciudadana para construir la paz ¿Cómo terminar la guerra? Más allá de la derrota o la negociación, ed. por Camilo González Posso, Kristian Herbolzheimer y Tathiana Montaña Mestizo (Bogotá: Instituto de Estudios para el Desarrollo y la Paz, Indepaz, 2010), 57-78, 59.

18 Cfr. María Cañadas Francesch et al., Alerta 2010! Informe sobre conflictos, derechos humanos y construcción de paz (España: Escola de Cultura de Pau (ECP) / Icaria), 19.

19 Cfr. "Acuerdo general para la terminación del conflicto y la construcción de una paz estable y duradera", firmado el 26 de agosto de 2012, en la Habana Cuba por el Gobierno de la República de Colombia y por las Fuerzas Armadas Revolucionarias de ColombiaEjército del Pueblo.

20 "Acuerdo final para la terminación del conflicto y la construcción de una paz estable y duradera", firmado a los 24 días del mes de noviembre de 2016 en Bogotá, Colombia; por Juan Manuel Santos Calderón, presidente de la República de Colombia; Timoleón Jiménez, comandante del Estado Mayor Central de las Farc-Ep, Bogotá: 24.11.2016.

21 Kristian Herbolzheimer, "Conflictos prolongados: similitudes y retos", en La vía ciudadana para construir la paz..., op. ci., 143-172, 155.

22 Paulo Freire, "Denuncia, anuncio, profecía, utopía y sueño" (1997), en Pedagogía de la indignación (Madrid: Morata, 2010), 129-146, 143. 
En definitiva, la paz exige la realización y el cumplimiento de las necesidades humanas básicas, que coinciden básicamente con la realización de los derechos humanos" ${ }^{23}$. En este sentido, cabe abordar algunas concepciones de los derechos humanos y de la paz, analizando su ineludible articulación.

Pese a que se utilizan distintas denominaciones, varias autoras y autores están de acuerdo en que el término más apropiado y más frecuente es el de derechos humanos. Bajo esta óptica, Gregorio Peces-Barba define los derechos fundamentales como "el conjunto de normas de un Ordenamiento jurídico, que forman un subsistema de éste, fundadas en la libertad, la igualdad, la seguridad y la solidaridad, expresión de la dignidad humana, que forman parte de la norma básica material de identificación del Ordenamiento, y constituyen un sector de la moralidad procedimental positivizada, que legitima al Estado Social y democrático de Derecho" ${ }^{24}$, perspectiva en la cual se ubica Colombia como país perteneciente a la órbita occidental. En este artículo se emplea el término derechos humanos, pero se asume que existen muchas definiciones, algunas de las cuales van acorde con las transformaciones socioeconómicas y políticas que permean los discursos y prácticas de los derechos humanos. Sus teorías se replantean y enriquecen en interrelación con las luchas de los movimientos sociales, las intersecciones que propician el reconocimiento de personas y grupos históricamente excluidos y la emergencia de nuevos derechos. En la actualidad varios/as autores/as proponen un diálogo intercultural de los derechos humanos, que desde posiciones contrahegemónicas permitan la elaboración de concepciones alternativas en búsqueda de sociedades más igualitarias y justas ${ }^{25}$. Siguiendo esta visión crítica, la educación en derechos humanos debe ampliar su mirada al estudio e investigaciones en este campo, incorporando diferentes aportes en esta materia.

En el mismo sentido, hay que reflexionar que en gran parte del mundo occidental existe una confluencia de criterios, según los cuales "la dignidad es el valor de la persona por el simple hecho de ser persona. Es el conocimiento que el ser humano tiene de las calidades que lo confirman como especie y el valor que ellas tienen en el contexto del universo" ${ }^{26} \mathrm{y}$ desde el punto de vista de esta cultura se considera que es el centro de los derechos humanos. Consecuentemente con las teorías críticas de los derechos humanos, varios/as autores/as difieren y explican que para otras culturas la dignidad humana tiene distintos significados y adquiere diferentes dimensiones, por lo tanto hay que revisar los planteamientos a la luz del diálogo intercultural para reconceptualizar los derechos humanos ${ }^{27}$, más allá de los presupuestos occidentales y liberales. En esta línea argumentativa, Helio Gallardo indica que "el principal desafío popular que plantean los derechos humanos es la distancia entre lo que se dice y se hace en

23 Xesús R. Jares, Educación y Derechos Humanos..., op. cit., 49.

24 Gregorio Peces-Barba M., Lecciones de Derechos Fundamentales, colab. de Rafael de Asís Roig y María del Carmen Barranco Avilés (Madrid, Instituto de Derechos Humanos Bartolomé de las Casas / Universidad Carlos III de Madrid / Editorial Dykinson, 2004 ), 42.

25 Boaventura de Sousa Santos, "Hacia una concepción intercultural de los Derechos Humanos", en Para descolonizar Occidente. Más allá del pensamiento abismal (Buenos Aires: ClACso / Prometeo Libros, 2010), 83-116.

26 Ligia Galvis Ortiz, Comprensión de los derechos humanos. Una visión para el siglo XXI (Bogotá: Ediciones Aurora, 4. ${ }^{a}$ ed. 2008 ), 45.

27 Boaventura de Sousa Santos, op. cit. 
este campo" 28 , de esta forma, no solo es necesario manejar las teorías sino poner en práctica los derechos humanos en la cotidianidad; esto se refiere tanto a las personas como a las instituciones y al Estado, es decir, pensar en ello adquiere una importancia vital en el proceder de la sociedad en las distintas situaciones. Así, en concordancia con esta perspectiva popular, los derechos humanos deben mirarse no solo desde las reivindicaciones específicas sino también ligados a los movimientos sociales. En Colombia se encuentran propuestas como las presentadas en la "Agenda Mínima de Paz elaborada por las organizaciones sociales populares que participan del espacio de Planeta $\mathrm{Paz}^{\prime 2}$, , para la reconstrucción ética y social del país, que garantice la no repetición del conflicto, bajo los principios de memoria, verdad, justicia y reparación. Esto implica trabajar por una cultura de derechos humanos que "se refiere al conjunto de valores, principios y normas basados en los derechos humanos que la persona incorpora como individuo para vivir en sociedad" ${ }^{30}$. Esta cultura es dinámica, y supone cambios a los cuales la educación debe estar atenta, para incorporar su análisis y discusión en la academia.

Para articular la relación interdependiente entre derechos humanos y paz, retomamos lo que Johan Galtung plantea sobre la paz. Este autor asume dos premisas: define la paz como la ausencia o la reducción de la violencia de todo tipo y, la paz como la transformación de los conflictos de forma creativa y no violenta; la última definición es más dinámica que la primera. Tomando como punto de partida estas dos visiones sobre la paz se hace alusión a la paz negativa y la paz positiva, que varios/as autores/as han abordado. En el marco de estas tendencias, Galtung se refiere específicamente a cinco denominaciones de paz, así:

Negative peace is the absence of violence of all kinds, en esta línea establece una tipología para la paz positiva.

Nature Peace, que corresponde a la cooperación de las especies y no a la pelea.

Direct positive peace; consistiría en la bondad verbal y física.

Structural positive peace; la libertad podría reemplazar a la represión y la igualdad a la explotación.

Cultural positive peace; la legitimación de la paz sustituiría la legitimación de la violencia ${ }^{31}$.

Xesús Jares, extiende la concepción de paz positiva, considerando que esta es un fenómeno amplio y complejo, su comprensión es multidimensional, la paz es un valor máximo de la existencia humana, la paz afecta todas las dimensiones de la vida (interpersonal, intergrupal, nacional, internacional), la paz hace referencia a una estructura social, la paz demanda igualdad y reciprocidad en las relaciones e interacciones, la paz significa condiciones y circunstancias deseadas, la paz hace referencia a tres conceptos relacionados entre sí: conflicto, desarrollo

28 Cfr. Helio Gallardo, Derechos humanos como movimiento social (Bogotá, Ediciones desde abajo, 2009), 19.

29 Cfr. Carlos Salgado Araméndez, op. cit., 67-68.

30 Asociación Pro Derechos Humanos de España, Cultura de Derechos Humanos (España: Ministerio de Asuntos Exteriores y de Cooperación, Gobierno de España), 25.

31 Johan Galtung, Peace by Peaceful Means. Peace and Conflict, Depelopment and Civilization (Oslo, International Peace Research Institute (PRIO), London, SAGE Publications, 1996), 9, 31-32 [nuestra traducción]. 
y derechos humanos y reafirma que la paz es un proceso dinámico ${ }^{32}$. Según Liduvina Poveda, la paz tuvo otros desarrollos en el siglo xx, concretamente "(...) En la década de los sesenta, con la aparición de los estudios para la paz como disciplina, la academia avanzó hacia un concepto de paz que sirvió para incluir otros referentes como la justicia social, la igualdad y el diálogo. A partir de entonces, con este avance se obtiene un panorama amplio de interpretación sobre el concepto de paz que puede ser 'negativa' o 'positiva'”, como se ha señalado ${ }^{33}$.

A su vez, Ligia Galvis efectúa un recuento sobre el derecho a la paz y afirma que "el medio idóneo para alcanzar la realización del derecho a la paz es el disfrute de todos los derechos humanos, de los derechos civiles, políticos, económicos, sociales y culturales" 34 , con lo cual complementa las ideas sobre la paz y fundamenta este derecho en su correspondencia mutua con los otros derechos humanos. Asimismo, los planteamientos sobre la paz están ligados con los acontecimientos a escala mundial, como la carrera armamentista en el marco de la Guerra Fría y la era nuclear del siglo xx; en este panorama, María Eugenia Rodríguez Palop se refiere a los antecedentes del derecho a la paz, aclarando que el origen de este derecho se ubica a principios de la edad moderna y que "la reivindicación de la paz, si bien, como es obvio, tiene una traducción en los Ordenamientos jurídicos nacionales (como un valor y un principio moral y político) y exige del Estado una determinada acción política, no puede desvincularse de las relaciones internacionales, para cuyo arbitraje se ha venido reivindicando desde sus orígenes" ${ }^{35}$, lo cual ayuda a consolidar y a promover lo concerniente a la paz en cada uno de los países, que como integrantes de la comunidad internacional se comprometen con esta responsabilidad. El derecho a la paz se contempla en la Declaración de Oslo sobre el Derecho Humano a la Paz; es así como la Conferencia General de la Organización de las Naciones Unidas para la Educación, la Ciencia y la Cultura, en su 29. a reunión celebrada en París del 21 de octubre al 12 de noviembre de 1997, expresó:

Artículo 1: La paz como derecho humano a) Todo ser humano tiene un derecho a la paz que es inherente a su dignidad de persona humana. La guerra y cualquier otro conflicto armado, la violencia en todas sus formas y cualquiera que sea su origen, así como la inseguridad de las personas son intrínsecamente incompatibles con el derecho humano a la paz. b) Todos los Estados y los demás miembros de la comunidad internacional deben garantizar, respetar y aplicar sin discriminación alguna el derecho humano a la paz, tanto en el plano interno como en el plano internacional ${ }^{36}$.

32 Xesús R. Jares, Educación para la paz..., op. cit., 102.

33 Liduvina Poveda Villafañe, "Sociedad civil y educación: reflexiones desde una perspectiva de paz", Revista Latinoamericana de Derechos Humanos 25, n. 1 (2014), 228.

34 Ligia Galvis Ortiz, op. cit., 205-206.

35 María Eugenia Rodríguez Palop, Claves para entender los nuevos derechos humanos (Madrid: Los Libros de la Catarata, 2011), $82,85$.

36 Unesco, Organización de las Naciones Unidas para la Educación, la Ciencia y la Cultura, Conferencia General 29a reunión, París, 1997 http://unesdoc.unesco.org/images/0011/001100/110027s.pdf (18 de noviembre de 2016). 
Ahora bien, Colombia comparte este ámbito internacional, acepta y ratifica sus compromisos en torno a la paz. Esto se establece dentro de su ordenamiento jurídico, lo cual se plasma en el artículo 22 de la Constitución Política de Colombia de 1991, afirmando que "la paz es un derecho y un deber de obligatorio cumplimiento" ${ }^{\prime 37}$. En este país, el derecho a la paz exige un marco en el que se materialicen los derechos individuales y colectivos, lo que constituye un reto para las sociedades, asunto en el que la interrelación entre las teorías y las prácticas ocupa un lugar privilegiado.Complementariamente, Adela Cortina afirma que "es necesario recordar una vez más que las declaraciones no son discursos neutrales, sino que declarar es comprometerse" ${ }^{\prime 38}$ y esto también es válido para el Estado colombiano, así que todas las fuerzas del país deben orientarse en concretar lo estipulado en la Constitución y en los documentos firmados. Las disquisiciones en torno a la paz resultan pertinentes para facilitar su comprensión, puesto que generalmente se asocia la paz con la inexistencia de conflictos, con la armonía total y con la idea de una paz pasiva ${ }^{39}$. Así, es importante resaltar que "el primer paso hacia la autenticidad es comprender y reconocer públicamente que el abordar cuestiones profundas y el compromiso de la gente, el diálogo sostenido, es un duro trabajo que no finaliza con un alto al fuego o la firma de un documento. El compromiso auténtico reconoce que el conflicto permanece. El diálogo es permanente, y exige plataformas que hagan posible y continuado tal compromiso en múltiples niveles de la sociedad afectada" ${ }^{40}$.

En Colombia, cuando se están tratando algunos aspectos de los contemplados en el Acuerdo final y se están desarrollando partes de los puntos de su agenda, es vital convocar la participación de la sociedad civil para su concreción, recordando que "la cultura de paz al igual que los conflictos, inciden en cada uno de los sectores de la sociedad, en lo económico, político, ecológico, social, cultural y educacional, tanto a nivel individual como social y estructural" ${ }^{11}$. Sin obviar lo anterior, el desafío es la reconciliación de la sociedad en el marco del proceso de paz, pues las experiencias demuestran que en escenarios posteriores hay un riesgo de volver a caer en situaciones de violencia, razón por la cual la paz se debe consolidar como política de Estado, apoyada irrestrictamente por todas las fuerzas políticas a las cuales la población también debería reclamar esa responsabilidad histórica. La etapa del posacuerdo implica un gran esfuerzo y el compromiso de toda la sociedad. Se debe consolidar la reconstrucción del tejido social, lo que seguramente abarcará a más de una generación. El reto será superar las dificultades para implementar reformas en un país con profundas

37 Constitución Política de Colombia, actualizada con los actos legislativos a 2013 (Bogotá: Edición especial preparada por el Consejo Superior de la Judicatura, Sala Administrativa-CENDOJ), 19.

38 Adela Cortina, op. cit., 65.

39 Cfr. Xesús R. Jares, Educación para la paz..., op. cit., 98-99.

40 John Paul Lederach, La imaginación moral. El arte y el alma de la construcción de la paz. Trad. por Teresa Toda (Colombia: Semana Libros, 2016), 109-110.

41 Isabel Hernández Arteaga, José Alberto Luna Hernández y Martha Cecilia Cadena Chala, "Cultura de paz: una construcción desde la educación”, Revista Historia de la Educación Latinoamericana, n. 28 (2017): 157. Ver tambien María Cristina Vera de Flachs "Notas para la Historia de la Universidad en Argentina” en Revista Historia de la Educación Latinoamericana, n.o. 8, (2006):65-112 
desigualdades y que ha vivido inmerso por largo tiempo en un conflicto armado interno, y como anota Gil Fell, lo que se necesita "son conceptos positivos que consideren la paz como una presencia activa de la justicia, de la igualdad, etc." ${ }^{42}$. Para lograr dichas transformaciones son claves las políticas públicas, la decidida actuación de los Gobiernos en todos sus niveles, el concurso de la empresa privada que apoye lo concerniente al desarrollo socioeconómico que conduzca a unas mejores condiciones de vida de todos los sectores poblacionales y la amplia participación democrática, sin exclusiones odiosas. La educación universitaria también juega en este terreno y requiere un sólido respaldo para cumplir sus tareas.

\section{El papel de la universidad en la educación en derechos humanos y para la paz}

La universidad, como parte de la comunidad académica de un país, cumple un papel cardinal en la formación de sus ciudadanos/as, lo que implica transformación, tanto en las teorías como en las prácticas en todos los ámbitos. La "Declaración sobre el derecho y el deber de los individuos, los grupos y las instituciones de promover y proteger los Derechos Humanos y las libertades fundamentales universalmente reconocidos", plantea en su artículo 15: "Incumbe al Estado la responsabilidad de promover y facilitar la enseñanza de los derechos humanos y las libertades fundamentales en todos los niveles de la educación $(. . .)^{\prime \prime 3}$, más allá de lo que aquí se estipula, se reflexiona que pese a las políticas públicas, en Colombia no se han tomado en serio estas cruciales actividades. En lo que aquí compete de forma directa, la universidad debe asumir un compromiso en todas las instancias para llevar a cabo esta labor, toda vez que, "(...) la ética pública que se transmite a través de la educación reglada en los programas escolares y universitarios y pretende orientar el juicio y la decisión de los códigos, comités y comisiones de bioética, de empresa, de las administraciones públicas, de las universidades o de los partidos públicos, apuesta por los derechos humanos $(. . .)^{\prime \prime 4}$, por lo cual aquí debe jugar todo el país, el sistema educativo y su máximo órgano rector, el Ministerio de Educación Nacional. Aunque en algunos países de América Latina y el Caribe se inicia un poco antes, a partir de 1990 se evidencia la mayor presencia del Estado en la educación en derechos humanos y la inclusión dentro de las políticas públicas. “También en esa década adquiere gran relevancia el papel de las universidades debido a la realización de importantes actividades en el ámbito de la educación en derechos humanos, sobre todo en las facultades de Ciencias Sociales, Derecho, Educación, Filosofía

\footnotetext{
42 Gil Fell, "Paz", en Educación para la paz. Cuestiones, principios y práctica en el aula, op. cit., 93-109, 94.

43 Naciones Unidas. Derechos Humanos. Oficina del Alto Comisionado, "Declaración sobre el derecho y el deber de los individuos, los grupos y las instituciones de promover y proteger los Derechos Humanos y las libertades fundamentales universalmente reconocidos. Comentario a la Declaración sobre el Derecho y el Deber de los individuos, los grupos y las Instituciones de promover y proteger los Derechos Humanos y las libertades fundamentales universalmente reconocidos" (Relatora especial sobre la situación de los defensores de los derechos humanos. Colombia, Guatemala y México, 2014), 153.

44 Adela Cortina, op. cit., 64.
} 
y Psicología, entre otras" ${ }^{\prime 4}$, lo cual también puede observarse en varias universidades de Colombia.

Cuando se piensa en el significado de la paz es imprescindible tener en cuenta que "la guerra es un desastre creado por la acción humana"46, razón por la cual se concatena con lo anterior, se aborda la educación para la paz desde el continuo interrogante sobre las dificultades, así como el desafío de posicionar y trabajar por lo que encarna la paz para superar los escenarios de violencia que conducen a la guerra ${ }^{47}$. Esto permite acercarse a las problemáticas en un emergente contexto de posacuerdos en la Colombia de 2016-2018, con el soporte de las pedagogías alternativas que propicien una continua interlocución con las comunidades para incorporar sus propuestas en la construcción de la paz. Puede afirmarse que las personas en Colombia tienen todas las posibilidades de transformar sus realidades y la universidad puede participar de forma activa para desarrollar ese potencial, pero se considera que el sistema educativo también tiene que modificarse. Señalan Jhon Diego Domínguez Acevedo y Ferney Quintero Ramírez que no se ha estudiado de forma suficiente el conflicto social y armado de Colombia, y tampoco todo lo relacionado con los avances en el proceso de paz. En esta línea, resaltan la importancia de involucrar estas temáticas dentro de lo que se denomina "la historia reciente en el currículo escolar" 48 , como un nuevo fin de la política educativa. Ahora bien, la universidad como centro de pensamiento se constituye en un espacio facilitador para el diálogo y la controversia, donde el debate fortalece la generación de ideas para gestionar, por vías pacíficas, los conflictos socio-económicos y políticos, que se presentan por diversas razones entre los seres humanos, “(...) el proceso de educación puede reforzar el sentido de la responsabilidad individual, la tendencia a concebir a los demás como individuos en sí mismos y la voluntad de manifestar opiniones críticas" ${ }^{\prime 9}$, el intercambio de puntos de vista contribuye a la deliberación franca y abierta. Al respecto, Mariela Inés Sánchez Cardona planteaba que los adelantos que estaban ocurriendo "en los temas de los acuerdos de paz en Colombia ameritan el compromiso de las instituciones educativas en la transformación de la cultura de la violencia por culturas de paz en la sociedad. De ellas dependerá en gran medida el empoderamiento que puedan tener las juventudes desde una visión crítica de los índices y niveles de violencia que son percibidos y legitimados en las interacciones que se dan en su diario vivir" 50 . En la actualidad, después de la firma del Acuerdo de Paz en Colombia, se continúa reivindicando la

45 Susana Beatriz Sacavino, Democracia y educación en derechos humanos en América Latina (Bogotá, Ediciones desde abajo, 2012 ), 76.

46 Johan Galtung, Tras la violencia, 3R...,op. cit., p. 15.

47 Luisa Fernanda Gualy, "Construcción de cultura de paz en América Latina desde la educación superior”, Revista de la Universidad de la Salle, n. 65 (2014): 54.

48 Jhon Diego Domínguez Acevedo y Ferney Quintero Ramírez, "La escuela en tiempos de post-acuerdo: enseñanza de la historia y contramemoria crítica", Fecode, Revista Educación y Cultura, n. 109 (2015): 26.

49 Martha C. Nussbaum, op. cit., $72-73$.

50 Mariela Inés Sánchez Cardona, "Hacia una propuesta de escuela sociocultural de la paz pedagógica en el postconflicto en Colombia", en Justicia Constitucional, t. I. Coord. por Ruth Carolina Blanco, comp. por María Constanza Ballesteros Moreno (Bogotá: Grupo Editorial Ibáñez, Universidad Santo Tomás, 2017), 199. 
relevancia de la educación en la formación ciudadana como componente básico en la construcción cotidiana de la paz.

En tal sentido, algunos antecedentes de la Universidad Pedagógica y Tecnológica de Colombia (UPTC) llevan a pensar en el papel de la educación universitaria como parte activa de la sociedad y, por ello, es imprescindible acercarse a sus aportes. Es pertinente señalar que, previas a la Ley n. ${ }^{\circ} 1732$, del $1 .^{\circ}$ de septiembre de 2014, "POR LA CUAL SE ESTABLECE LA CÁTEDRA DE LA PAZ EN TODAS LAS INSTITUCiONES educativas del país", aprobada por el Congreso de Colombia, en la uptC se han desarrollado varias experiencias. La UPTC se interesa en estas problemáticas y, conforme a su misión, se compromete a formar seres humanos íntegros, pensantes, críticos, dialogantes, respetuosos y solidarios. Con una visión amplia, la universidad puede liderar procesos educativos que coadyuven a este gran proyecto que es la paz positiva. El Estado es un actor cardinal frente a la paz, que debe conducir este proyecto toda vez que "la construcción de paz demanda transformaciones que permitan desmontar los determinantes mediatos e inmediatos de los ciclos de violencia" 51 , su accionar no puede restringirse al sentido de pactos y debe poner en marcha lo negociado en los acuerdos. Johan Galtung considera que la paz positiva es la mejor protección contra la violencia ${ }^{52}$ y avanza un esquema que puede orientar algunos temas de investigación o acción en el campo de la educación, por supuesto, teniendo en cuenta los diversos contextos. A continuación se transcribe la tabla que el autor elabora, donde resalta lo que denomina tipologías mínimas: N (Nature), P (Person), S (Social), W (World), C (Culture), T (Time) ${ }^{53}$.

Systematization II of Peace and Conflict Studies: Some Examples of Fields of Education, Research, Action

\begin{tabular}{ll}
\hline Direct violence $(D V)$ & Direct (positive) peace (DP) \\
N: 'survival of the fittest' & N: 'mutual aid and cooperation' \\
P: violence to Self, suicide & P: intra-, inter-personal growth \\
S: violence across fault-lines & S: nonviolent liberation \\
W: war geography; genocide & W: peace movements; alternative de- \\
& fense \\
C: culturocide & C: cultural liberation \\
T: history and future of violence, war & T: history and future of peace \\
Structural violence (SV) & Structural (positive) peace (SP) \\
N: ecocide & N: non-homocentric eco-peace \\
P: psychopathologies & P: intra-, inter-personal peace \\
S: patriarchy, racism, class & S: development, parity, equity \\
W: imperialism, trade & W: peace regions; governance, UN
\end{tabular}

51 Camilo González Posso, "La vía ciudadana hacia la paz: aportes a una política de construcción de paz 2010 -- 2020 ", en La vía ciudadana para construir la paz..., op. cit., 17-56, 53.

52 Positive peace is the best protection against violence. Johan Galtung, Peace by peaceful means, op. cit., 32

53 Cfr. "Typology", en Johan Galtung, Ibíd., 30 [nuestra traducción]. 
C: cultural imperialism

T: history and future of exploitation and repression

Cultural violence ( $\mathrm{CV}$ )

Religion: transcendent

Law: democracy, human rights

Ideology: universalist, singularist

Language: sexist, racist

Art: patriotic, patriarchic

Science I: Western logic?

Sciencie II: to destroy life

Cosmology: Occident I? Sinic? Nipponic?

School: militarization

University: militarization

Media: war-violence journalism
C: cultural coexistence

T: sustainability of the above

Cultural (positive) peace (CP)

Religion: immanent

Law: democracy, human rights

Ideology: particularist, pluralist

Language: humanist/non-speciesist

Art: humanist/non-speciesist

Science I: Daoist? Buddhist?

Science II: to enhance life

Cosmology: Occident II? Indic? Buddhic?

School: peace education

University: peace study and research

Media: peace journalism

Fuente: Table 2.2., Johan Galtung, Peace by peaceful means. Peace and Conflict, Development and Civilization, Oslo: International Peace Research Institute (PRIO), London, SAGE Publications, 1996, 33.

En esta línea de pensamiento, Johan Galtung, conocedor del caso de Colombia, plantea una terapia dentro de la cual señala una serie de remedios. Recomienda tener en cuenta el diagnóstico que se realice y trabajar en todos los factores simultáneamente. Para lo que compete en forma directa a la universidad, nos detendremos en el punto "(...) 3) Introducir educación de paz y conflictos en los currículos de las escuelas, poniendo a disposición textos con 50-100 historias de manejos exitosos no-violentos y creativos de conflictos, como puntos de referencia para la vida" ${ }^{54}$, teniendo presente las características de cada región, de las zonas urbanas y rurales, así como la representación de todos los grupos sociales. Ahora bien, observando la situación de Colombia y atendiendo los aportes teóricos y recomendaciones de Johan Galtung, desde las universidades se pueden elaborar propuestas. Como se ha mencionado, la UPTC viene realizando esta tarea que sin duda debe ser más amplia, integrarse a los lineamientos curriculares y mejorarse de forma constante. Siguiendo el esquema elaborado por Johan Galtung y reproducido antes, hay que señalar que, si bien fue hecho hace más de veinte años, resulta pertinente y actual en muchos aspectos. A partir de lo allí expuesto es posible proyectar sugerencias concretas tomando como referencia las categorías y tipologías que el autor formula. Se anotan algunas situaciones específicas que se podrían trabajar en Colombia en el campo de la educación,

54 Johan Galtung, "Colombia: una perspectiva Transcend”, en Estado y ciudadanía para la paz, investigadores Laura Camila Ramírez Bonilla et al. (Bogotá: Observatorio de Construcción de Paz, Universidad de Bogotá Jorge Tadeo Lozano; Fondo para la Sociedad Civil por la Paz la Democracia y los Derechos Humanos, Serie documentos para la paz, 2011),101-105, 102, 104. 
investigación y acción. Así, frente a ciertas formas de violencia directa (Direct violence $(D V)$ ) se esbozan propuestas orientadas a la paz positiva (Direct (positive) peace $(D P))$, retomando postulados de diversos/as autores/as que aportan sobre determinadas cuestiones planteadas en las tipologías, lo que a manera de ejemplo se expone a continuación:

\begin{tabular}{|c|c|}
\hline Direct violence (DV) & Direct (positive) peace (DP) \\
\hline S: violencia across fault-lines & $\begin{array}{l}\text { S: nonviolent liberation } \\
\text { Luchas contrahegemónicas } \\
\text { Comprensión popular de las luchas por los derechos } \\
\text { humanos }^{56}\end{array}$ \\
\hline W: war geography; genocide & $\begin{array}{l}\text { W: peace movements; alternative defense } \\
\text { Movimientos sociales a favor y en defensa de los dere- } \\
\text { chos humanos y la paz }\end{array}$ \\
\hline C: culturocide & C: cultural liberation \\
\hline $\begin{array}{l}\text { T: history and future of violence, } \\
\text { war }\end{array}$ & $\begin{array}{l}\text { T: history and future of peace } \\
\text { Historia de Colombia y de los procesos de diálogos y } \\
\text { Acuerdos de paz }\end{array}$ \\
\hline Structural violence (SV) & Structural (positive) peace (SP) \\
\hline$N$ : ecocide & $\begin{array}{l}N \text { : non-homocentric eco-peace }{ }^{57} \\
\text { Movimientos ecologistas }\end{array}$ \\
\hline S: patriarchy, racism, class & $\begin{array}{l}\text { S: development, parity, equity } \\
\text { Estudios de géneros/feminismos, intersecciones }{ }^{58} \\
\text { igualdad, no discriminación }\end{array}$ \\
\hline C: cultural imperialism & $\begin{array}{l}\text { C: cultural coexistence } \\
\text { Movimientos sociales anti-globalización (MAG). Cultu- } \\
\text { ras poscapitalistas }^{59}\end{array}$ \\
\hline $\begin{array}{l}\text { T: history and future of exploita- } \\
\text { tion of exploitation and repres- } \\
\text { sion }\end{array}$ & $\begin{array}{l}\text { T: sustainability of the above } \\
\text { No exclusion }\end{array}$ \\
\hline
\end{tabular}

55 Boaventura de Sousa Santos, La caída del Angelus Novus: Ensayos para una nueva teoría social y una nueva práctica política, Colombia (Colombia: ILSA, Universidad Nacional de Colombia, Ediciones Antropos Ltda., 2003), 213-217 y Arturo Escobar, Una minga para el postdesarrollo: Lugar, medio ambiente y movimientos sociales en las transformaciones globales (Bogotá: Ediciones desde abajo, 2012), 49 .

56 Helio Gallardo, op cit, 19-138.

57 Ecologismo vs medioambientalismo, María Eugenia Rodríguez Palop, op. cit., 89-112.

58 Cfr. Nira Yuval-Davis, "Más allá de la dicotomía del reconocimiento y la redistribución" y Avtar Brah, "Pensando en y a través de la interseccionalidad", en La interseccionalidad en debate. Actas del Congreso Internacional "Indicadores Interseccionales y Medidas de Inclusión Social en Instituciones de Educación Superior", eds. Martha Zapata Galindo, Sabina García Peter y Jennifer Chan de Avila, Berlín, 23 - 27 de noviembre de 2012 (Berlín: 2013, Lateinamerika-Institut der Freien Universität Berlin), 21-34, 22 y 14-20, 14. María José Guerra Palmero, "Derechos Humanos, intersección de opresiones y enfoques crítico-feministas", Derechos con Razón. Filosofía y Derechos Humanos, coords. Cristina Corredor Lanas y Javier Peña Echeverría (España: Fundación Aranzadi Lex Nova, Observatorio de Derechos Humanos Universidad de Valladolid, 2013), 49-69.

59 Arturo Escobar, op. cit., 47, 49, 57, 147. 


\begin{tabular}{|c|c|}
\hline Cultural violence (CV) & Cultural (positive) peace (CP) \\
\hline Law: democracy, human rights & $\begin{array}{l}\text { Law: democracy, human rights } \\
\text { Democracia, derechos humanos }\end{array}$ \\
\hline $\begin{array}{l}\text { Ideology: universalist, singular- } \\
\text { ist }\end{array}$ & $\begin{array}{l}\text { Ideology: particularist, pluralist } \\
\text { Política pública de derechos humanos. } \\
\text { Derechos de las víctimas y enfoque diferencial } \\
\text { pluralismo, diálogo intercultural }^{60}\end{array}$ \\
\hline Language: sexist, racist & $\begin{array}{l}\text { Language: humanist/non-speciesist } \\
\text { Lenguaje: humanista, no sexista, ni racista, ni discri- } \\
\text { minatorio }\end{array}$ \\
\hline Art: patriotic, patriarchic & Art: humanist/non-speciesist \\
\hline $\begin{array}{l}\text { Cosmology: Occident I? Sinic? } \\
\text { Nipponic? }\end{array}$ & $\begin{array}{l}\text { Cosmology: Occident II? Indic? Budhic? } \\
\text { Cosmología y conocimientos de los pueblos origina- } \\
\text { rios } \\
\text { (Indígenas), poblaciones afrodescendientes, etc. Diá- } \\
\text { logo de saberes }\end{array}$ \\
\hline School: militarization & $\begin{array}{l}\text { School: peace education } \\
\text { Sistema educativo: educación en derechos humanos y } \\
\text { para la paz }\end{array}$ \\
\hline University: militarization & $\begin{array}{l}\text { University: peace study and research } \\
\text { Universidad: Estudios, investigaciones y publicacio- } \\
\text { nes sobre conflictos, derechos humanos y la paz. } \\
\text { Educación y pedagogía de la memoria }{ }^{61} \text {. }\end{array}$ \\
\hline Media: war-violence journalism & $\begin{array}{l}\text { Media: peace journalism } \\
\text { Medios de comunicación democráticos que promue- } \\
\text { van la paz y el respeto por los derechos humanos de } \\
\text { todas las personas y grupos. }\end{array}$ \\
\hline
\end{tabular}

Fuente: Tomado de "Systematization II of Peace and Conflict Studies: Some Examples of Fields of Education, Research, Action", Table 2.2., Johan Galtung, Peace by peaceful means.

Peace and Conflict, Development and Civilization. Oslo: International Peace Research Institute (PRIO), London, SAGE Publications, 1996, 33 (adaptado por las autoras de este artículo).

Esta es una propuesta que puede ser enriquecida de manera interdisciplinaria y permanente, en consonancia con los movimientos sociales contemporáneos, las realidades y la ampliación del catálogo de derechos humanos. Hay varios/as autores/as que se refieren a las luchas contrahegemónicas, a partir de las cuales se vienen construyendo una serie de alternativas a modelos hegemónicos que prescinden de amplios sectores de la población, recortándoles

60 Boaventura de Sousa Santos, "Hacia una concepción..., op. cit., 83-116.

61 María Andrea Rocha Solano, "Pedagogía de la historia y las memorias en contextos políticos turbulentos", en Narrativas de experiencia en educación y pedagogía de la memoria, comp. por Gabriel Jaime Murillo Arango (Buenos Aires: Editorial de la Facultad de Filosofía y Letras, Universidad de Buenos Aires, 2015), 337-368. 
cualquier posibilidad de mejorar sus condiciones de vida. Arturo Escobar toma como ejemplo la histórica exclusión en Colombia, evidenciada en la profunda desigualdad, concentración del ingreso y, por tanto, pobreza ${ }^{62}$. Los feminismos desarrollan teorías en concordancia con los movimientos de mujeres. Dentro de sus muchos aportes pueden señalarse las "intersecciones", que tienen en cuenta las circunstancias, opresiones, impugnaciones, subversiones, resistencias, avances y planteamientos de la diversidad de mujeres o sus organizaciones, intersecciones que además abarcan a toda la población y se encuentran en diálogo con puntos de vista similares. También sirven de guía publicaciones como la de Medófilo Medina y Óscar Murillo, Colombia por un país humano y plural ${ }^{63}$ en la que compendian la educación de la democracia, los derechos humanos y la violencia en Colombia, teniendo en cuenta su población originaria: indígenas, afrodescendientes, mestizos, así como la diversidad de regiones, la inflexión de la Constitución Política de 1991 y sus alcances.

La reflexión desde la universidad debe articularse con las experiencias de amplios sectores de la población que aportan al proceso de construcción de paz y puede ser, en la práctica, una muestra del compromiso social de la universidad del siglo xxI, como sugiere Boaventura de Sousa Santos, cuando anota que "la resistencia debe involucrar la promoción de alternativas de investigación, de formación, de extensión y de organización que apunten hacia la democratización del bien público universitario, es decir, para la contribución específica de la universidad en la definición y solución colectiva de los problemas sociales, nacionales y globales" ${ }^{\prime 64}$. Pensando en esa universidad la academia debe seguir trabajando interna y externamente. Óscar Guardiola conmina a las personas a convertir el proceso de paz "en un encuentro transformador y creativo" 65 y aquí la universidad tiene mucho que decir y proponer en materia de educación en derechos humanos y para la paz. Desde esta óptica puede afirmarse que hay propuestas formativas como "La Escuela en Democracia y Paz (...) a partir de la opción pedagógica por la concepción de la educación popular en derechos humanos" ${ }^{\prime 66}$, que podrían aportar a la universidad otros modos de acercarse y compartir con las organizaciones y a su vez aprender de las iniciativas locales en materia de derechos humanos. Cabe recordar que la pedagogía, como actividad humana sistemática, permite orientar las acciones educativas planteando principios, métodos y prácticas dentro de otros elementos y por ello, "La pedagogía crítica es un enfoque educativo que intenta deliberadamente influenciar en

62 Cfr. Arturo Escobar, op. cit., 68.

63 Medófilo Medina y Óscar Murillo Ramírez, Colombia por un país humano y plural (Ecuador: Corporación Editora Nacional, 2013).

64 Boaventura de Sousa Santos, La universidad en el siglo xxi. Para una reforma democrática y emancipadora de la universidad (Bolivia: CIDES-UMSA, ASDI y Plural editores, 2007, 4. ${ }^{\text {a }}$ ed. en castellano), 57.

65 Óscar Guardiola Rivera, Cómo construir sociedades. Diez cosas que nunca nos dicen sobre la paz y la guerra (Bogotá, Pontificia Universidad Javeriana, 2014), 38.

66 María del Pilar Bernal Gómez y Camilo Enrique Jiménez Camargo, Educación popular en derechos humanos y construcción de paz (Bogotá: Corporación Podion, 2011), 23. 
cómo y qué conocimiento e identidades se producen en cada relación de poder y contexto particular" ${ }^{\prime \prime 7}$.

Con el mismo enfoque, Paulo Freire propone erigir una pedagogía de la movilidad que implica un movimiento y apertura al cambio y a la diferencia: "ustedes no se imaginan lo que se aprende con alguien diferente (...) una pedagogía del movimiento es una pedagogía de apertura hacia el otro, el diferente ${ }^{\prime \prime 6}$, afirma Freire, y esta pedagogía de la movilidad supone un esfuerzo individual y grupal para realmente aprender a conocer a las demás personas y reconocer en la diferencia un valor que permite acercarse sin odios a otros proyectos, dialogar y llegar a acuerdos que privilegien lo que se denomina el bien público y se beneficien los intereses colectivos por encima de los privados, con miras a que la población pueda participar plenamente de una vida digna que se concrete en un buen vivir. Todo esto posibilita "pedagogizar la paz", en palabras de Carlos Aldana, lo que significa que en el "esfuerzo educativo por la paz no queda fuera la tarea de descubrir profunda y científicamente por qué la paz está ausente" ${ }^{\prime \prime 6}$ y este es uno de los desafíos de la universidad a través de sus debates, diálogo de saberes, investigaciones y publicaciones, sin dejar de lado la memoria histórica, pues como hace notar Gabriel Murillo, "el ejercicio de la memoria histórica"70 no ha contado con espacios amplios en la escuela y no se ha desarrollado teniendo en cuenta su importancia en un país que ha mantenido un largo conflicto armado. Con esperanza puede afirmarse que en adhesión a El Manifiesto de Sevilla sobre la Violencia, donde se expresa que si "nuestros antepasados inventaron la guerra, nosotros podemos inventar la paz"71, la universidad se convierte en el laboratorio social propicio donde confluyen las experiencias de las distintas generaciones para "imaginar"72 la paz.

\section{CONCLUSIÓN}

El estudio desde un enfoque crítico e inderdisciplinario de los conflictos, los derechos humanos y la paz, en su fuerte interacción, puede contribuir a la formulación de elementos que coadyuven a una cultura de paz. A pesar de las diferencias, se puede aprender a valorar a todos los seres humanos, a respetar los derechos de las personas, sin ningún tipo de discriminación. Los conflictos están presentes en todas las sociedades y las experiencias demuestran que también

67 Abraham Magendzo-Kolstrein y María Isabel Toledo-Jofré, "Educación en derechos humanos: Estrategia pedagógica-didáctica centrada en la controversia”, Revista Electrónica Educare 19, n. ${ }^{\circ} 3$ (2015): 1-16, http://www.revistas.una.ac.cr/index.php/EDUCARE/rt/ printerFriendly/6864/7037 (20 de noviembre de 2016), 4.

68 Paulo Freire, El grito manso (Buenos Aires: 2. ${ }^{\text {a }}$ ed. 3. ${ }^{a}$ reimp., Siglo xxI, 2010), 60-61.

69 Carlos Aldana Mendoza, Desafíos pedagógicos de la paz (Guatemala: Universidad de San Carlos de Guatemala, Oficina de Derechos Humanos del Arzobispado, Editorial Universitaria, 1995), 14, 16.

70 Gabriel Jaime Murillo Arango. "Los trabajos y los días de una pedagogía de la memoria", en Narrativas de experiencia en educación y pedagogía de la memoria, op. cit., 313-335, 314.

71 "El Manifiesto de Sevilla sobre la Violencia. Preparar el terreno para la construcción de la paz", en Educación para la paz. Cuestiones, principios y práctica en el aula, op. cit., 293-295, 295.

72 Rodrigo Uprimny, "Imaginar la paz", El Espectador, Bogotá, 17 de octubre de 2015. 
pueden resolverse a través del diálogo intercultural mediante sociedades verdaderamente democráticas en las cuales tengan cabida las opiniones contrarias. La educación en estas temáticas se convierte cada vez más en un imperativo en el que se debe implicar el sistema educativo, además de las familias, las empresas privadas, los medios de comunicación y, desde luego, el Estado, que tiene la obligación de orientar y concretar estos procesos a través de las políticas públicas, así como garantizar los derechos humanos.

La importancia de educar en derechos humanos y para la paz cobra protagonismo al considerar la necesidad de hacer evidente el compromiso individual y colectivo de los actos de cada quien. Las personas, como agentes morales, tienen la capacidad de formarse en el reconocimiento de las otras/os y el respeto a la diferencia de los seres humanos.

En este marco, las universidades y entre ellas la UPTC, juegan un transcendental papel y tienen el compromiso de reflexionar sobre estas problemáticas e incorporarlas, con ayuda de las pedagogías alternativas, en sus programas, investigaciones, publicaciones $y$, en general, en todas sus actividades, entre las que se incluyen la elaboración de propuestas como una necesidad para participar activamente en la estructuración de una sociedad justa y equitativa. Se resalta la pedagogía crítica que como enfoque educativo intenta de forma deliberada influenciar en cómo y qué conocimiento e identidades se producen en cada relación de poder y contexto particular, puesto que la formación de ciudadanas y ciudadanos, que puedan potenciar sus capacidades y la articulación entre las teorías y las prácticas, se hacen más evidentes en el propósito común de la consecución de la paz positiva.

Ahora bien, pese a que el Gobierno del presidente Juan Manuel Santos firmó en noviembre 2016 el Acuerdo Final con uno de los actores armados, se observa que aún en etapa de posacuerdos, pensar en la paz resulta difícil, entre otras muchas razones porque la población que ha vivido en entornos de conflictos armados - en medio, de un lado o del otro-, parecería que se hubiera acostumbrado a ello. Como la mayoría de estas personas no ha experimentado lo que significa vivir en paz su comprensión se dificulta y por ello se deben aunar todos los esfuerzos orientados a argumentar la relevancia de la educación en derechos humanos y para la paz, haciendo que el proceso de construcción de una paz estable y duradera sea prioridad para la sociedad colombiana, generando una apropiación colectiva con el fin de que la paz sea posible y se convierta en realidad, para lo cual también se requiere la transformación de las condiciones socioeconómicas, culturales y políticas del país.

Por lo tanto, la reflexión desde la universidad debe articularse con las experiencias de amplios sectores de la población que han aportado al proceso de construcción de paz y puede ser, en la práctica, una muestra del compromiso social de la universidad del siglo xxI.

Así, una propuesta que puede ser enriquecida de manera interdisciplinaria y permanente, en consonancia con los movimientos sociales contemporáneos, las realidades y la ampliación del catálogo de derechos humanos, es la de consi- 
derar temas y asignaturas (dentro de los diversos programas académicos de las diferentes facultades de la universidad) como los sugeridos y orientados a la paz positiva ya expuestos en este artículo, a saber:

- Luchas contrahegemónicas.

- Comprensión popular de las luchas por los derechos humanos.

- Movimientos sociales a favor y en defensa de los derechos humanos y la paz.

- Historia de Colombia y de los procesos de diálogos y acuerdos de paz.

- Movimientos ecologistas.

- Estudios de géneros/feminismos, intersecciones, igualdad, no discriminación.

- Movimientos sociales anti-globalización (MAG). Culturas poscapitalistas.

- No exclusión.

- Política pública de derechos humanos.

- Derechos de las víctimas y enfoque diferencial.

- Pluralismo, diálogo intercultural.

- Lenguaje: humanista, no sexista, ni racista, ni discriminatorio.

- Cosmología y conocimientos de los pueblos originarios (indígenas), poblaciones afrodescendientes, etc. Diálogo de saberes.

- Sistema educativo: educación en derechos humanos y para la paz.

- Universidad: Estudios, investigaciones y publicaciones sobre conflictos, derechos humanos y la paz.

- Educación y pedagogía de la memoria.

- Medios de comunicación democráticos que promuevan la paz y el respeto por los derechos humanos de todas las personas y grupos.

Como corolario final cabe reiterar que a la universidad le compete el reto y la responsabilidad de contribuir en la formación en derechos humanos y para la paz como aporte transcendental para la sociedad colombiana, lo que puede hacerse realidad con el apoyo de las pedagogías alternativas que faciliten a la educación universitaria cumplir con su función de educar personas empoderadas y con argumentos. Esta postura posibilita "pedagogizar la paz" tomando como base desarrollar la noción de una cultura de derechos que tenga como finalidad la defensa de la dignidad humana, la libertad, la igualdad, la solidaridad, la justicia, la democracia y la paz.

\section{REFERENCIAS}

"Acuerdo final para la terminación del conflicto y la construcción de una paz estable y duradera", firmado a los 24 días del mes de noviembre de 2016 en Bogotá, Colombia; por Juan Manuel Santos Calderón, Presidente de la República de Colombia; Timoleón Jiménez, Comandante del Estado Mayor Central de las Farc-Ep. Bogotá: 24 de nov. de 2016.

"Acuerdo general para la terminación del conflicto y la construcción de una paz estable y duradera", firmado el 26 de agosto de 2012, en La Habana, Cuba, por el Gobierno de la República de Colombia y por las Fuerzas Armadas Revolucionarias de Colombia-Ejército del Pueblo.

Aldana Mendoza, Carlos. Desafíos pedagógicos de la paz. Guatemala: Universidad de San Carlos de 
Guatemala, Oficina de Derechos Humanos del Arzobispado, Editorial Universitaria, 1995.

Asociación Pro Derechos Humanos de España. Cultura de Derechos Humanos (España: Ministerio de Asuntos Exteriores y de Cooperación, Gobierno de España).

Bernal Gómez, María del Pilar y Camilo Enrique Jiménez Camargo. Educación popular en derechos humanos y construcción de paz. Bogotá: Corporación Podion, 2011.

Brah, Avtar. "Pensando en y a través de la interseccionalidad". En La interseccionalidad en debate. Actas del Congreso Internacional "Indicadores Interseccionales y Medidas de Inclusión Social en Instituciones de Educación Superior", editado por Martha Zapata Galindo, Sabina García Peter y Jennifer Chan de Avila, 14-20 (23 - 27 de noviembre de 2012). Berlín: Lateinamerika-Institut der Freien Universität Berlin, 2013.

Burnley, Jen. "Conflicto". Educación para la Paz. Cuestiones, principios y práctica en el aula, compilado por David Hicks, 73- 92. Madrid: Ministerio de Educación y Cultura, Morata, 1999.

Butler, Judith. Violencia de Estado, guerra, resistencia. Por una nueva política de izquierda (entrevista de Daniel Gamper Sachse). Traducción de Patricia Soley-Beltran. España: Centro de Cultura Contemporánea de Barcelona, 2011.

Cañadas Francesch, María, Vicenç Fisas Armengol, Patricia García Amado et al. Alerta 2010! Informe sobre conflictos, derechos humanos y construcción de paz. España: Escola de Cultura de Pau (ECP) / Icaria, 2009.

Constitución Política de Colombia de 1991. Actualizada con los actos legislativos a 2013. Bogotá: Edición especial preparada por el Consejo Superior de la Judicatura, Sala Administrativa-CENDOJ.

Cortina, Adela. Aporofobia, el rechazo al pobre. Un desafío para la democracia. España: Paidós, 2017.

Domínguez Acevedo, Jhon Diego y Ferney Quintero Ramírez. "La escuela en tiempos de post-acuerdo: enseñanza de la historia y contramemoria crítica". Fecode, Revista Educación y Cultura, n. ${ }^{\circ} 109$ (2015): 23-30.“El Manifiesto de Sevilla sobre la Violencia. Preparar el terreno para la construcción de la paz". En Educación para la Paz. Cuestiones, principios y práctica en el aula, compilado por David Hicks, 293-295. Madrid: Ministerio de Educación y Cultura, Morata, 1999.

Escobar, Arturo. Una minga para el postdesarrollo: Lugar, medio ambiente y movimientos sociales en las transformaciones globales. Bogotá: Ediciones desde abajo, 2012.

Fell, Gil. "Paz". En Educación para la Paz. Cuestiones, principios y práctica en el aula, compilado por David Hicks, 93-109. Madrid: Ministerio de Educación y Cultura, Morata, 1999.

Freire, Paulo. El grito manso. Buenos Aires: 2. ${ }^{a}$ ed., 3. ${ }^{a}$ reimp. Siglo xxI, 2010.

Freire, Paulo. "Denuncia, anuncio, profecía, utopía y sueño" (1997). En Pedagogía de la Indignación, traducido por Tomás del Amo, 129-146. Madrid: Morata, 2010.

Gallardo, Helio. Derechos humanos como movimiento social. Bogotá: Ediciones desde abajo, 2009.

Galvis, Ligia. Comprensión de los derechos humanos. Una visión para el siglo XXI. Bogotá: Ediciones Aurora, 4. ${ }^{\mathrm{a}}$ ed. 2008.

Galtung, Johan. Peace by Peaceful Means. Peace and Conflict, Development and Civilization. Oslo: International Peace Research Institute (PRIO), London, sAGE Publications, 1996.

Galtung, Johan. Tras la violencia, 3R: reconstrucción, reconciliación, resolución. Afrontando los efectos visibles e invisibles de la guerra y la violencia, traducido por Teresa Toda. Bilbao: Bakeaz, Gernika Gogoratuz, 1998.

Galtung, Johan. "Colombia: una perspectiva Transcend". En Estado y ciudadanía para la paz, investigadores Laura Camila Ramírez Bonilla et al., 101-105. Bogotá: Observatorio de Construcción de Paz, Universidad de Bogotá Jorge Tadeo Lozano; Fondo para la Sociedad Civil por la Paz la Democracia y los Derechos Humanos, Serie documentos para la paz, 2011.

González Posso, Camilo. "La vía ciudadana hacia la paz: aportes a una política de construcción de paz 2010 - 2020". En La vía ciudadana para construir la paz ¿Cómo terminar la guerra? Más allá de la derrota o la negociación. Editado por Camilo González Posso, Kristian Herbolzheimer y Tathiana Montaña Mestizo, 17-56. Bogotá: Instituto de Estudios para el Desarrollo y la PaZ, INDEPAZ, 2010.

Guardiola Rivera, Óscar. Cómo construir sociedades. Diez cosas que nunca nos dicen sobre la paz y la guerra. Bogotá: Pontificia Universidad Javeriana, 2014. 


\section{educación en derechos humanos y para la paz}

Gualy, Luisa Fernanda. “Construcción de cultura de paz en América Latina desde la educación superior". Revista de la Universidad de la Salle, n. ${ }^{\circ} 65$ (2014): 51-84.

Guerra Palmero, María José. “Derechos Humanos, intersección de opresiones y enfoques crítico-feministas". En Derechos con Razón. Filosofía y Derechos Humanos, coordinado por Cristina Corredor Lanas y Javier Peña Echeverría, 49-69. España: Fundación Aranzadi Lex Nova, Observatorio de Derechos Humanos Universidad de Valladolid, 2013.

Herbolzheimer, Kristian. Conflictos prolongados: Similitudes y Retos. En La vía ciudadana para construir la paz ¿Cómo terminar la guerra? Más allá de la derrota o la negociación, editado por Camilo González Posso, Kristian Herbolzheimer y Tathiana Montaña Mestizo, 143-172. Bogotá: Instituto de Estudios para el Desarrollo y la Paz, INDEPAZ, 2010.

Hernández Arteaga, Isabel, José Alberto Luna Hernández y Martha Cecilia Cadena Chala, “Cultura de paz: una construcción desde la educación". Revista Historia de la Educación Latinoamerica$n a,{ }^{\circ} 28$ (2017): 149-172.

Jares, Xesús R. Educación para la paz. Su teoría y su práctica. Madrid: Editorial Popular, 1991.

Jares, Xesús R. Educación y Derechos Humanos. Estrategias didácticas y organizativas. Madrid: Editorial Popular, 1999.

Lederach, John Paul. La imaginación moral. El arte y el alma de la construcción de la paz. Traducido por Teresa Toda. Colombia: Semana Libros, 2016.

Magendzo-Kolstrein, Abraham y María Isabel Toledo-Jofré. "Educación en derechos humanos: Estrategia pedagógica-didáctica centrada en la controversia". Revista Electrónica Educare 19, n. 3 (2015): 1-16, http://www.revistas.una.ac.cr/index.php/EDUCARE/rt/printerFriendly/6864/7037 (20/11/ 2016)

Medina, Medófilo y Óscar Murillo Ramírez. Colombia por un país humano y plural. Ecuador: Corporación Editora Nacional, 2013.

Murillo Arango, Gabriel Jaime. "Los trabajos y los días de una pedagogía de la memoria". En Narrativas de experiencia en educación y pedagogía de la memoria, compilado por Gabriel Jaime Murillo Arango, 313-335. Buenos Aires: Editorial de la Facultad de Filosofía y Letras Universidad de Buenos Aires, 2015.

Naciones Unidas. Derechos Humanos. Oficina del Alto Comisionado, Declaración sobre el derecho y el deber de los individuos, los grupos y las instituciones de promover y proteger los Derechos Humanos y las libertades fundamentales universalmente reconocidos. Comentario a la Declaración sobre el Derecho y el Deber de los individuos, los grupos y las Instituciones de promover y proteger los Derechos Humanos y las libertades fundamentales universalmente reconocidos (Relatora especial sobre la situación de los defensores de los derechos humanos. Colombia, Guatemala y México, 2014), 148-154.

Nussbaum, Martha C. Sin fines de lucro. Por qué la democracia necesita de las humanidades. Traducción María Victoria Rodil. Madrid: Katz Editores, 2010.

Ortega Valencia, Piedad. "Las urgencias de una cátedra de la paz en la escuela: Rutas de formación". Fecode, Revista Educación y Cultura, n. ${ }^{\circ} 109$ (2015): 8-14.

Peces-Barba M., Gregorio. Lecciones de Derechos Fundamentales, colaboración de Rafael de Asís Roig y María del Carmen Barranco Avilés. Madrid: Instituto de Derechos Humanos Bartolomé de las Casas, Universidad Carlos III de Madrid, Dykinson, 2004.

Porter, Elisabeth. Construir la paz. La experiencia y el papel de las mujeres en perspectiva internacional. Traducido por Diego Luis Sanromán. Barcelona: Institut Català Internacional per la Pau (ICIP), Edicions Bellaterra, S. L., 2012.

Poveda Villafañe, Liduvina. "Sociedad civil y educación: reflexiones desde una perspectiva de paz". Revista Latinoamericana de Derechos Humanos 25, n. 1 (2014): 227-241.

Programa de las Naciones Unidas para el Desarrollo, PNuD. “De la violencia a la Sociedad de los Derechos: Propuesta de Política Integral de Derechos Humanos 2014-2034", coordinadores editoriales Ítalo Andrés Velásquez y Carlos Alberto Rivera (Bogotá: Proceso Tripartito de Construcción Participativa de la Política Pública de DDHH y DIH, PNUD, 2013).

Rocha Solano, María Andrea. "Pedagogía de la historia y las memorias en contextos políticos turbulentos". En Narrativas de experiencia en educación y pedagogía de la memoria, compilado por Gabriel Jaime Murillo Arango, 337-368. Buenos Aires: Editorial de la Facultad de Filosofía y 
Letras Universidad de Buenos Aires, 2015.

Rodríguez Palop, María Eugenia. Claves para entender los nuevos derechos humanos. Madrid: Los Libros de la Catarata, 2011.

Roth D., André-Noël. Discurso sin compromiso. La política pública de derechos humanos en Colombia. Antecedentes históricos de los derechos humanos. Qué es una política pública. Actitud del Estado colombiano. Bogotá: Ediciones Aurora, 2006.

Sacavino, Susana, "Educación para la paz y la No Violencia en la formación de docentes". La Tarea. Traducido por Cecilia Botana, n. 20 (2009): 12-18.

Sacavino, Susana Beatriz. Democracia y educación en derechos humanos en América Latina. Trad. Cecilia Botana. Bogotá: Ediciones desde abajo, Bogotá, 2012.

Sánchez Cardona, Mariela Inés. "Hacia una propuesta de escuela sociocultural de la paz pedagógica en el postconflicto en Colombia". En Justicia Constitucional, t. I. Coordinado por Ruth Carolina Blanco, compilado por María Constanza Ballesteros Moreno, 199-222. Bogotá: Grupo Editorial Ibáñez, Universidad Santo Tomás, 2017.

Santos, Boaventura de Sousa. La caída del Angelus Novus: Ensayos para una nueva teoría social y una nueva práctica política. Colombia: ILSA, Universidad Nacional de Colombia, Ediciones Antropos Ltda., 2003.

Santos, Boaventura de Sousa. La Universidad en el siglo xxi. Para una reforma democrática y emancipadora de la universidad. Bolivia: CIDEs-UMSA, ASDi y Plural editores, 2007, $4 .^{\text {a }}$ ed. en castellano.

Santos, Boaventura de Sousa. "Hacia una concepción intercultural de los Derechos Humanos". En Para descolonizar Occidente. Más allá del pensamiento abismal, 83-116. Buenos Aires: clacso, Prometeo Libros, 2010.

Salgado Araméndez, Carlos. "Proyecto planeta paz. Estrategia social de construcción de paz". En La vía ciudadana para construir la paz. ¿Cómo terminar la guerra? Más allá de la derrota o la negociación, editado por Camilo González Posso, Kristian Herbolzheimer y Tathiana Montaña Mestizo, 57-78. Bogotá: Instituto de Estudios para el Desarrollo y la Paz, INDEPAZ, 2010.

Unesco. Organización de las Naciones Unidas para la Educación, la Ciencia y la Cultura.Conferencia General 29. ․ㅜ reunión, París 1997. http://unesdoc.unesco.org/images/0011/001100/110027s. pdf. (18/11//2016).

Uprimny, Rodrigo. "Imaginar la paz". El Espectador, Bogotá, 17 de octubre de 2015.

Yuval-Davis, Nira. "Más allá de la dicotomía del reconocimiento y la redistribución". En La interseccionalidad en debate. Actas del Congreso Internacional "Indicadores Interseccionales y Medidas de Inclusión Social en Instituciones de Educación Superior", editado por Martha Zapata Galindo, Sabina García Peter y Jennifer Chan de Avila, 21-34. (23 - 27 noviembre 2012). Berlín: 2013, Lateinamerika-Institut der Freien Universität Berlin.

Vera de Flachs, María Cristina "Notas para la Historia de la Universidad en Argentina" en Revista Historia de la Educación Latinoamericana, n.o. 8, (2006):65-112

Zuleta, Estanislao. Sobre la guerra. Cali: Universidad del Valle. http://catedraestanislao.univalle.edu. $\mathrm{co} /(22 / 11 / 2015)$.

\begin{tabular}{l|l|} 
& \\
\hline & Como citar: \\
Trimiño Velásquez, Celina; Amézquita Aguirre, Luisa. & \\
“Reflexiones desde la universidad sobre educación en derechos \\
humanos y para la paz" Revista Historia de la Educación \\
Latinoamericana. Vol. 20 No. 31 (2018): 101-124 \\
DOI: 10.19053/01227238.8564
\end{tabular}

